DOI 10.17816/transsyst201842152-166

\author{
(C) R. Kircher ${ }^{1}$, J. Klühspies ${ }^{1}$, R. Palka ${ }^{2}$, E. Fritz ${ }^{3}$, K. Eiler $^{1}$, M. Witt ${ }^{1}$ \\ ${ }^{1}$ The International Maglev Board \\ (Deggendorf, Germany) \\ ${ }^{2}$ Department of Power Systems \& Electrical Drives, West Pomeranian \\ University of Technology \\ (Szczecin, Poland) \\ ${ }^{3}$ IfB - Institut für Bahntechnik \\ (Dresden, Germany)
}

\title{
ELECTROMAGNETIC FIELDS RELATED TO HIGH SPEED TRANSPORTATION SYSTEMS
}

Issue: The potential health risks on passengers and the environment related to electromagnetic fields caused by the operation of electrically driven high speed transportation systems has become a major issue. Especially the magnetic flux density or induction can generate physiological effects in body tissues.

Aim: In this paper, we compare calculated and experimental values of electromagnetic fields in rail-wheel systems such as ICE with the Maglev-systems Transrapid and the JR Maglev-system, based on available data.

Methods: To estimate the impact on passengers, the field contributions generated by the power supply system as well as by the drive and suspension systems are taken into account. For the comparison, the peak values of the electromagnetic fields have been considered.

Results: The results show, that there are no health risks from the electric fields. Regarding the magnetic induction, the calculated the peak values remain well below the limits given by national regulations. In the case of the Transrapid and the JR Maglev system, the measured peak values in the environment and inside the vehicle depend on the levitation and the guidance technology and the geometrical parameters. The JR Maglev system requires effective magnetic shielding measures which are connected with heavy materials. Since such materials may have a negative influence on the energy balance and the economics of operation, R\&D efforts are focusing on the optimization of materials and the structure of shields.

Conclusion: In high speed transportation systems there are no potential risks from electrical fields. Regarding magnetic fields, the induction generated by the power supply and the drive system remain well below the frequency dependent limits. The situation is different for magnetic levitation systems, depending on the suspension and guidance technology. Especially the JR Maglev requires effective shielding measures. The shielding materials may have a negative impact on the energy balance.

Keywords: Electromagnetic fields, Physiological effects, Health risks, High speed transportation systems, Rail-wheel systems, ICE, Transrapid, Maglev 


\section{INTRODUCTION}

Biological effects of electromagnetic fields are among the most serious environmental concerns in the public regarding health risks and quality of life.

The physiological effects of electrical, magnetic and electromagnetic fields on the human body are dependent on the frequency. The effects of static electric fields are limited to the surface of the human body and can cause motion of body hair and corona discharges.

Static magnetic fields exert forces on ferro- and diamagnetic materials as well as charged moving particles. This may lead to acceleration, torque effects and the induction of electric fields in the tissue.

In the low-frequency range up to some $100 \mathrm{kHz}$ the main physiological effect is the electrical stimulation of excitable body tissues like muscles, nerves and sensory organs. Biological effects on nerves and other tissue of the body caused by induced currents are dominating. In the high frequency (HF) range thermal effects are increasingly important [1].

Because all electromagnetic fields (EMF) related biological effects in the low-frequency range are linked to peak values in the internal electrical field strength and magnetic flux density in body tissues all exposure limit values of the fields have to be taken into account. To reduce risks for health limits are imposed on the emission of electromagnetic fields (EMF). Table 1 shows the limits for the electric field strength and the magnetic induction for the different frequency ranges, as imposed by the German regulation BImSchV 26. In the case of high speed transportation systems, the low frequency range has to be considered, from static fields to frequencies up to about $1 \mathrm{kHz}$.

Table 1. Limits for the emission of electromagnetic fields, valid in Germany provided by the regulation BImSchV 26. The magnitude $f$ is the frequency

\begin{tabular}{|c|c|c|}
\hline $\begin{array}{c}\text { Frequency } \\
(\mathbf{H z})\end{array}$ & $\begin{array}{c}\text { Electric field strength } \\
(\mathbf{k V} \text { per meter })\end{array}$ & $\begin{array}{c}\text { Magnetic induction } \\
(\boldsymbol{\mu} \text { Tesla) }\end{array}$ \\
\hline 0 & - & 500 \\
\hline $1-8$ & 5 & $40000 / \mathrm{f}$ \\
\hline $8-25$ & 5 & $5000 / \mathrm{f}$ \\
\hline $25-50$ & 5 & 200 \\
\hline $50-400$ & $250 / \mathrm{f}$ & 200 \\
\hline $400-3000$ & $250 / \mathrm{f}$ & $80000 / \mathrm{f}$ \\
\hline $3000-10000000$ & 0.083 & 27 \\
\hline
\end{tabular}

The article compares the electromagnetic fields generated by high speed transportation systems by a typical railway system and Maglev systems, based on available data. As examples for the comparison, the German high speed train ICE, the German magnetic levitation system Transrapid (TR), and the Japanese Maglev systems have been selected. The present comparison is focusing on the 
electromagnetic field distribution and its influence to the passengers and on the environment outside. In the comparison, the maximum values of the electrical and magnetic fields are calculated.

In other European countries and Overseas similar upper limits exist, depending on the corresponding regulations.

In electrically powered high speed transportation systems, several contributions to the electromagnetic field distribution have to be considered:

1) Fields generated by the power supply system (external and internal);

2) Fields generated by the drive / motor system.

Other contributions from air condition and lighting are neglected in this comparison.

\section{BASIC PHYSICAL RELATIONS}

\section{Electrical field}

The maximum electrical field strength $\mathrm{E}_{\max }$ is defined as

$$
E_{\max }=U_{d} / d[\mathrm{~V} / \mathrm{m}],
$$

where $\mathrm{U}_{0}$ is the peak voltage and $\mathrm{d}$ the distance from the origin of the source of the field.

\section{Magnetic field} by

The maximum magnetic field strength or magnetic induction $\mathrm{B}_{\max }$ is given

$$
B_{\max }=\mu_{0} I_{0} /(2 \pi \mathrm{r})[\mathrm{T}],
$$

where $\mu_{0}$ is the air permeability with a value of $4 \pi \times 10^{-7} \mathrm{Vs} /(\mathrm{Am}), \mathrm{I}_{0}$ the peak current value, and $r$ the distance from the wire or the current conductor.

The shielding of electrical fields can be realized in a simpler way than the shielding of magnetic fields since the metallic body of a train acts as a Faraday cage, shielding the internal space from low frequency electrical fields.

The efficient shielding of magnetic fields requires the application of special materials (ferromagnetic or superconducting). Therefore, much more attention has to be paid to emission of the magnetic fields generated by currents of the power supply and the drive system. These currents are determined by the power and the voltage level. The focus of the current investigation concerns the peak values of the power related magnetic fields. 


\section{RESULTS}

\section{Railway system}

The power is supplied by substations feed by public or railway owned high voltage power grid to the transportation system via high voltage (HV) overhead wires. In general, the voltage level of AC systems is $15 \mathrm{kV}$ or $25 \mathrm{kV}$ with a frequency of 16.7 respectively $50 \mathrm{~Hz}$. The maximum driving power is applied during acceleration of the train. The electrical peak power may achieve a value of several MW. The corresponding current value is in the range between several hundreds and a few kA along the pathway.

The drive system within the transportation equipment consists of inverters and three phase motors with a voltage level up to $2 \mathrm{kV}$. The frequency is in the range between 0 and $200 \mathrm{~Hz}$ [2]. The nominal operational speed considered for the ICE 3 is up to $330 \mathrm{~km} / \mathrm{h}$.

In general, two different situations for the exposure to electromagnetic fields have to be considered: 1. the emission of electromagnetic fields to the external environment, i.e. the impact to the neighbouring environment of the railway line, and 2. the exposure of passengers inside the train.

\section{Calculation of the electrical field}

1) The electrical field strength at a distance of $25 \mathrm{~m}$ from the overhead wire with a voltage of $25 \mathrm{kV}$ is $\mathrm{E}=1000 \mathrm{~V} / \mathrm{m}$, which is well below the limit of $5000 \mathrm{~V} / \mathrm{m}$ given in Table 1 . Field strengths of $1 \mathrm{kV} / \mathrm{m}$ will cause in body tissue only a small electrical field of about $1 \mathrm{mV} / \mathrm{m}$ [1].

2) The estimation of the electrical field within the train is more complicated. The distance from the overhead wire is smaller but, on the other hand, the metallic roof of the wagon represents an electrical shielding. Therefore, the impact of the electrical fields from power supply of railway systems on the neighbouring environment and on passengers can be neglected.

\section{Calculation of the magnetic field (induction)}

To estimate the magnetic field or induction generated by the overhead power line, we have to consider the number of trains running within one section between 2 substations where the power is fed-in. At the newly, in Germany constructed ICE line between Nuremberg and Berlin, a typical distance between 2 substations is about $25 \mathrm{~km}$. With 2-3 trains per hour in both directions, we can restrict to consider the power for 2 trains within the same section, only. In other words, the peak current in the overhead power line for at least 2 trains within this section could reach the value of $2 \times 850 \mathrm{~A}$ in the case of $15 \mathrm{kV}$. At $25 \mathrm{kV}$ the current is correspondingly lower. The magnetic induction generated by the peak current of $1700 \mathrm{~A}$ at a distance of $25 \mathrm{~m}$ from the overhead power line is $13.6 \mu \mathrm{T}$, which lies well below the limit of $300 \mu \mathrm{T}$ for the frequency of $16.7 \mathrm{~Hz}$. Therefore, the impact of the magnetic field from the outside power supply to the 
neighbouring environment along the railway line can be neglected.

The determination of the magnetic field or induction inside the train is more complicated. In the rail-wheel system and the example of the ICE 3, the power is supplied via the inverter stages to the motors. In case of the ICE, the mechanical power reaches $8000 \mathrm{~kW}$ at transition speed, respectively at the maximum speed of $330 \mathrm{~km} / \mathrm{h}$, delivered to 16 motors, each motor with a power of $500 \mathrm{~kW}$. The driving concept consists of 16 motors, divided into 4 sections with 4 motors in each section [2]. We therefore focus on one section which supplies a power of $2000 \mathrm{~kW}$. The power is delivered to the motors via a 3 stage transformation/conversion system: A single phase transformer transforms the voltage of $25 \mathrm{kV}$ or $15 \mathrm{kV}$ from the overhead line at the frequency of $50 \mathrm{~Hz}$ respectively $16.7 \mathrm{~Hz}$ to $2 \times 1100 \mathrm{~V}$. At the second stage, the AC voltage of $1100 \mathrm{~V}$ is converted into a DC voltage of $2800 \mathrm{~V}$ by 2 converters. At the third stage, the DC voltage is again converted to a 3-phase $\mathrm{AC}$ voltage ranging from 0 to $2000 \mathrm{~V}$ and a variable frequency in the range from 0 to $200 \mathrm{~Hz}$ which is applied to the 4 motors. As a result, a maximum efficient current value of $250 \mathrm{~A}$ is flowing to each motor at a constant speed of $330 \mathrm{~km} / \mathrm{h}$ on a flat track.

For the calculation of the magnetic field inside the train, the current values at each stage have to be considered, in addition to the field induced by the external overhead wire. Since these values are taken from the efficient power, the maximum or peak values have to be used for the estimation of the peak magnetic field by

$$
\mathrm{I}_{\mathrm{p}}=\mathrm{I}_{0}=\mathrm{I}_{\mathrm{eff}} \times \sqrt{ } 2
$$

The effective current value at the secondary side of the transformer is about $900 \mathrm{~A}$, the peak value $1273 \mathrm{~A}$, at each of the 2 output lines with an output voltage of $1100 \mathrm{~V}$. The maximum current value at the output of the two AC-DC converters is $1010 \mathrm{~A}$, and the 3-phase DC-AC inverter delivers currents to the 4 motors up to 4 times 353 A (for the effective power of $250 \mathrm{~kW}$ of each motor. However, we have to consider that the 4 motors are distributed along the section.

The resulting magnetic induction generated by the components of the power supply system in one section, the transformer, the converter and the inverter feeding the motors is shown as a function of the distance from the system component in Fig. 1. However, we have to keep in mind, that there is some shielding of the stray fields by the material of the component containment. Especially for the stray field of the transformer much lower values than in Fig. 1 can be assumed due to the shielding of the containment. 


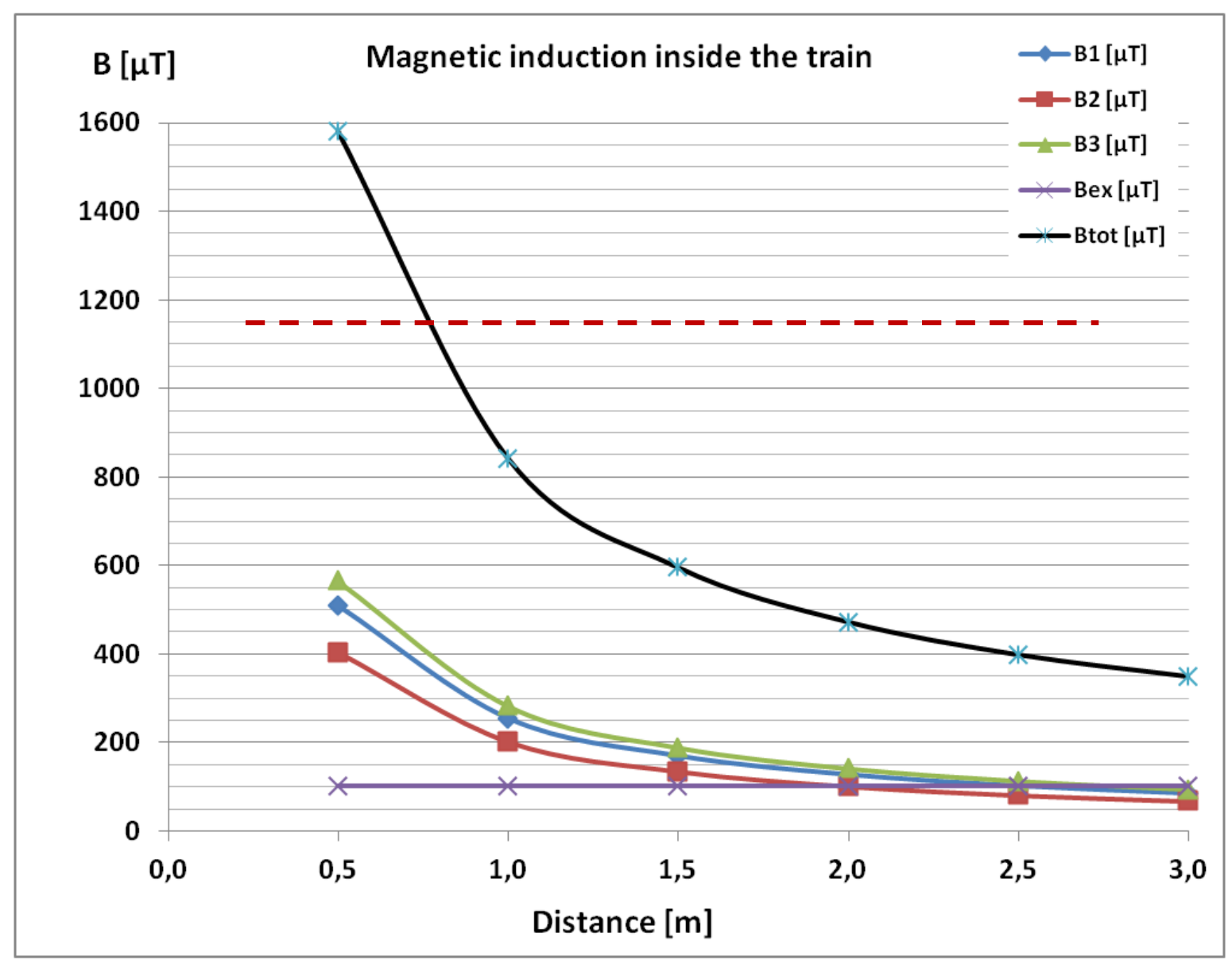

Fig. 1. The maximum magnetic induction generated by:

- the transformer $\left(\mathrm{B}_{1}\right)$,

- the converter $\left(\mathrm{B}_{2}\right)$,

- the inverter currents to the motors $\left(\mathrm{B}_{3}\right)$

as function of the distance from the source of the magnetic field (system component)

$\mathrm{B}_{\mathrm{ex}}$ is the field generated by the external overhead wires in both directions

$\mathrm{B}_{\mathrm{tot}}$ is the sum of all magnetic field contributions

It is clearly seen that most of the contribution to the magnetic induction is caused by the large currents from the inverter to the motors $\left(\mathrm{B}_{3}\right)$. However, the four motors are distributed over the driven train section. The external field from the 2 overhead power lines is of minor influence, only. By adding the maximum values of all 4 contributions at a distance of $1 \mathrm{~m}$, the total induction $B_{\text {tot }}$ would peak around $800 \mu \mathrm{T}$. However, this is a theoretical and not a realistic value. Comparing with the frequency dependent limits of $300 \mu \mathrm{T}(16.7 \mathrm{~Hz}), 500 \mu \mathrm{T}$ (DC) and $200 \mu \mathrm{T}(200 \mathrm{~Hz})$ in Table 1, all field contributions remain well below the limits inside the train. In addition, the body of the wagon will further reduce the concentration of the magnetic field inside the train. The total magnetic induction inside the train depending on the distance from the location of the generated field is shown in Fig. 2. 


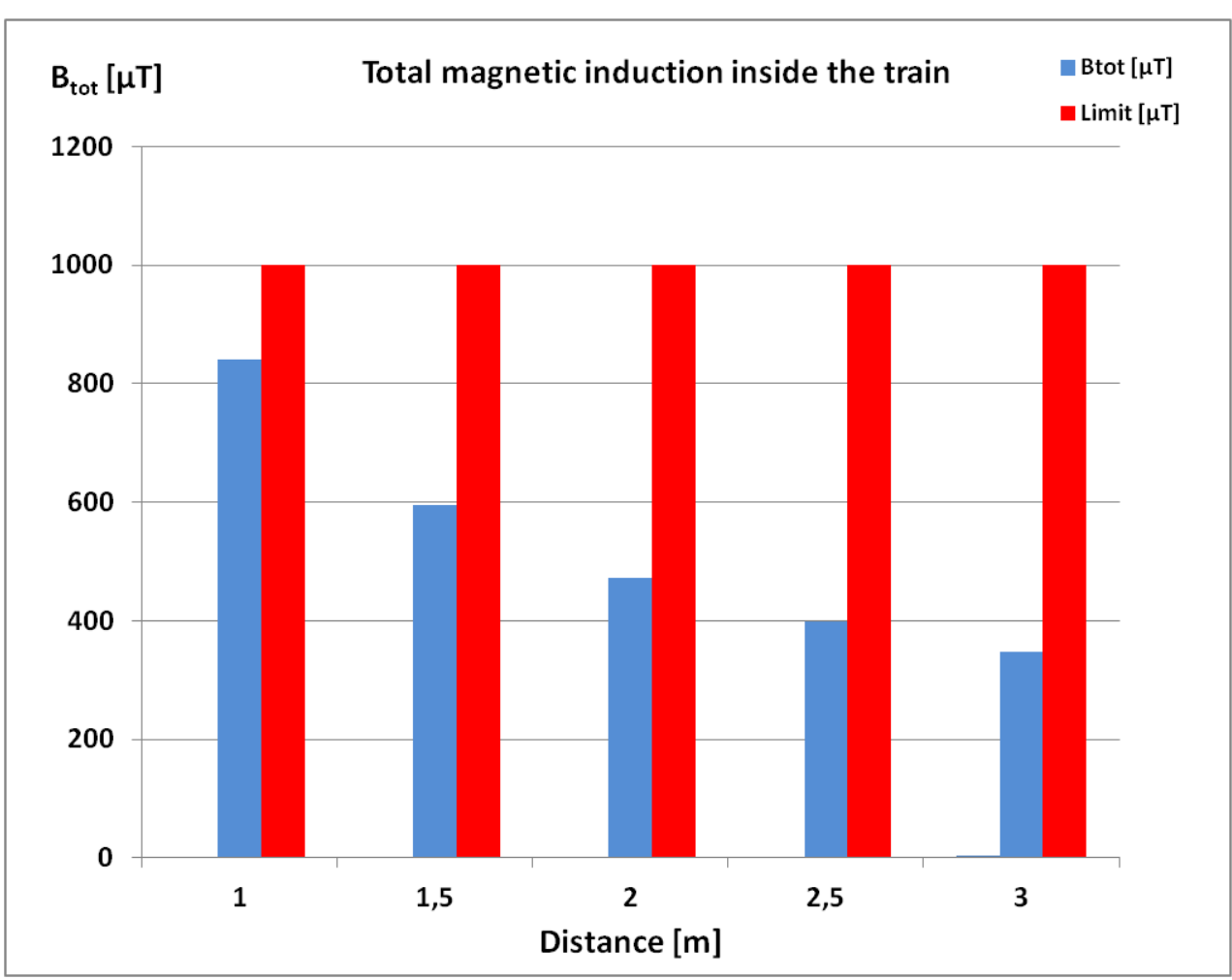

Fig. 2. The maximum total magnetic induction as a function of the distance from the location of the field generation.

\section{Maglev systems}

Maglev systems are propelled by linear motors. The power for the levitation system, the guidance and the propulsion is supplied via coils integrated into the guide way (track). As a consequence, electrical fields can be neglected, only magnetic fields have to be taken into account. In this article we compare the German system Transrapid and the Japanese system Linear Chuo Shinkansen. The Transrapid system is based on normal conductor magnet technology EMS, whereas the Japanese system is based on the superconducting Maglev technology EDS, using onboard superconducting magnets and normal conducting coils for levitation, guidance and propulsion integrated along the guide way [6].

\section{1) Transrapid system}

The Maglev system has no wheels, axles, transmissions, or pantographs. It does not roll; it hovers. Electronic systems guarantee that the clearance remains constant (nominally $10 \mathrm{~mm}$ ). To hover, the Transrapid requires less power than its air conditioning equipment. The levitation system and all onboard electronics are supplied by the power recovered from harmonic oscillations of magnetic field of the track's linear stator (Those oscillations being parasitic cannot be used for propulsion anyway) at speeds above $100 \mathrm{~km} / \mathrm{h}$, while at lower speeds power is obtained through physical connections to the track. In case of power failure of the track's propulsion system Transrapid vehicle uses on-board backup batteries 
that can supply power to the levitation system, which is therefore independent of the propulsion system.

Electronically controlled support magnets located on both sides along the entire length of the vehicle pull the vehicle up to the ferromagnetic stator packs mounted to the underside of the guide way. Guidance magnets located on both sides along the entire length of the vehicle keep the vehicle laterally on the track. Electronic systems guarantee that the clearance remains constant. To levitate the Transrapid requires less power than its air conditioning equipment. The vehicle is capable of hovering up to one hour without external energy. While travelling, the on-board batteries are recharged by linear generators integrated into the support magnets.

The Transrapid Maglev system uses a synchronous long-stator linear motor both for propulsion and braking. The linear motor is functioning like a rotating electric motor whose stator is cut open and stretched along under the guide way. The synchronous long-stator motor is divided in sections (typical stator length ranges between 500 and $2000 \mathrm{~m}$ ) due to economic reasons (reduce losses) and reasons of propulsion.

Inside the motor windings, alternating current generates a magnetic traveling field which moves the vehicle without contact. The support magnets in the vehicle function as the excitation portion (rotor). The respective magnetic traveling field works in only one direction, and therefore makes moving train collisions less likely, as more than one train on the track section would travel in the same direction.

Recent developments suggest a reduction of the high voltage level in the propulsion system from previously $2-10 \mathrm{kV}$ to a voltage level between $400-900 \mathrm{~V}$ along the line, with a frequency of $50 \mathrm{~Hz}$ [3]. The power is transmitted along propulsion sections of the guide way. Substations switch the power only in that section in which a vehicle is moving. Other sections are switched off and free of power. Fields are generated by the bearing system, the guidance and the linear drive system. The structure of the TR08 system is illustrated in Fig. 3.

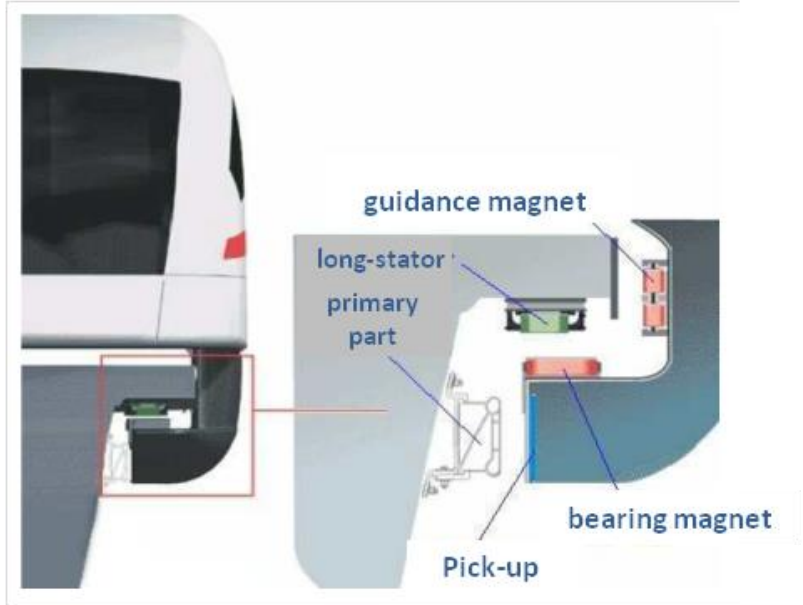

Fig. 3. Structure of the bearing and propulsion system of TR08 [4] 
The nominal operational speed chosen for the comparison is $430 \mathrm{~km} / \mathrm{h}$. For the TR08 system of the Transrapid exist a wide basis of available information and experimental data by measurement.

We consider the magnetic field or induction in the neighbourhood of the guide way (track), as well as inside the vehicle.

The magnetic field or induction and its frequency dependence along the track is shown in Fig. 3a. The induction is lower than $10 \mu \mathrm{T}$, even very close to the guideway. There is no impact to be expected for residential areas. The reason for the low induction values is the small gap between the bearing and the guidance magnets and the stator coils in the vehicle. This drastically reduces the stray fields outside the guideway.

The situation is different inside the vehicle. Since the linear motor coils are located in the vicinity of the floor of the vehicle, they generate higher induction values inside, as illustrated in Fig. 3b. The maximum value is, as expected, just on the floor with a maximum value up to more than $25 \mu \mathrm{T}$, depending on the frequency. With increasing distance to the floor, the induction values decrease. All values are below the limits of the BImSchV 26, and even much lower than those of the rail-wheel system ICE3. For comparison, the earth magnetic field is in the range of $30-50 \mu \mathrm{T}$, depending on geographical location.

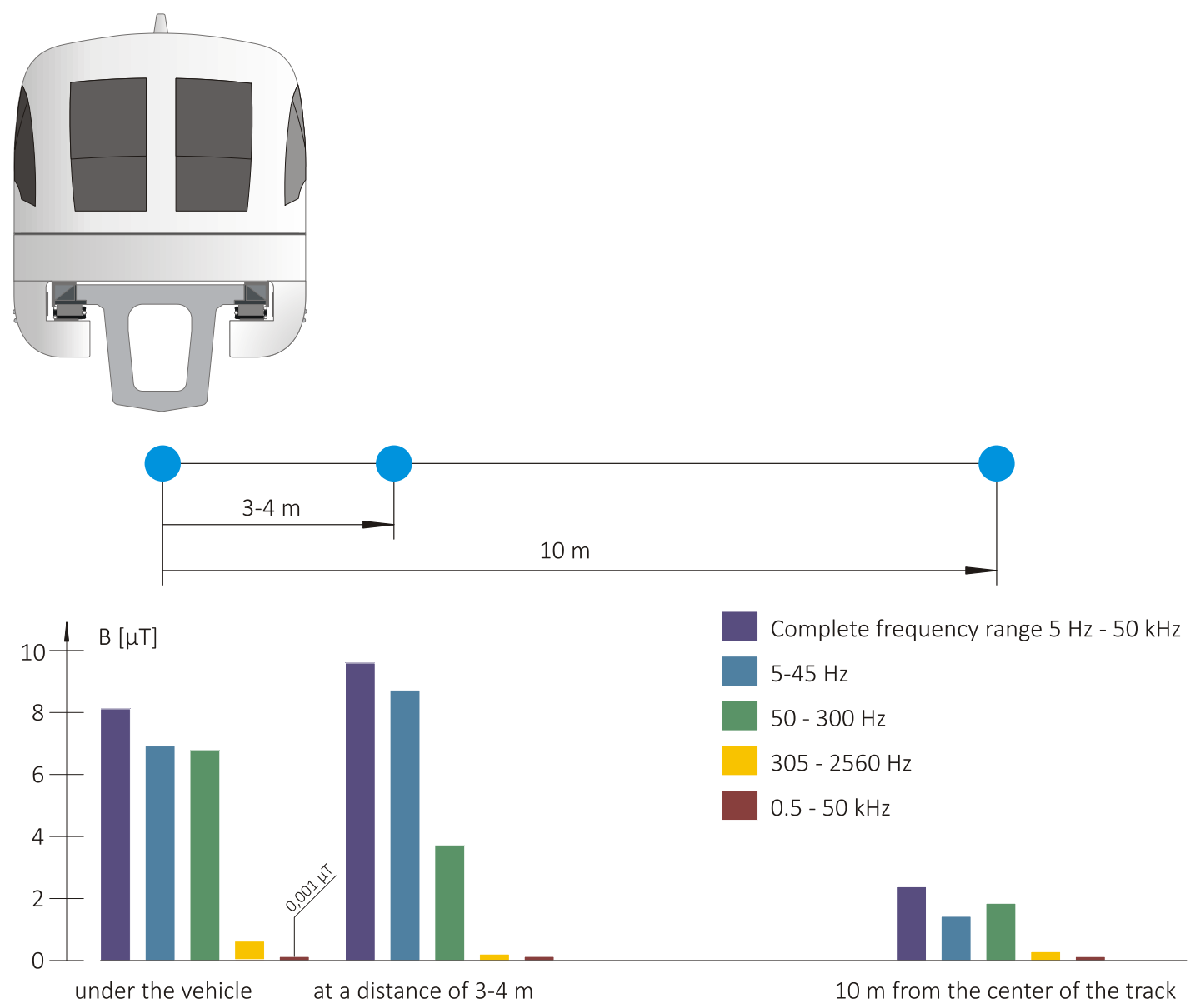

Fig. 4a. Magnetic induction along the track [5] 


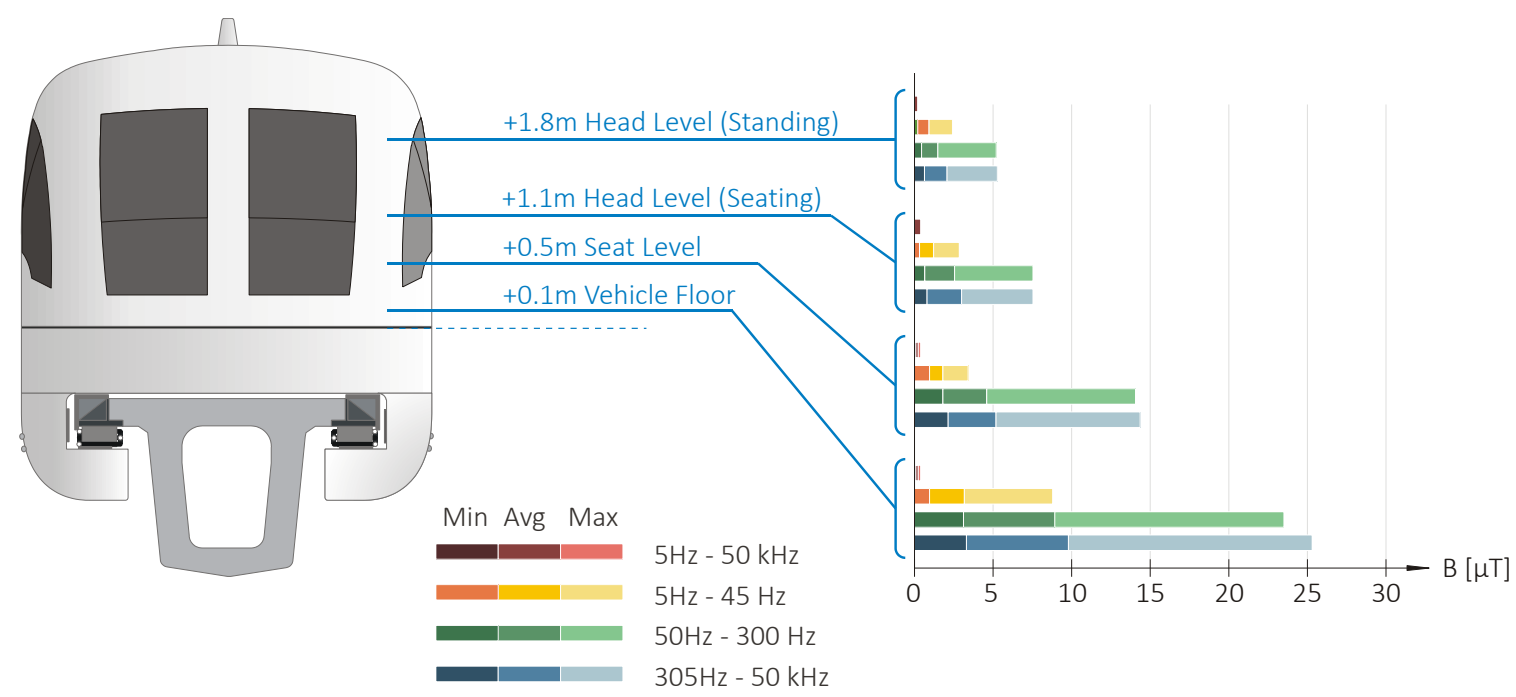

Fig. 4b. Magnetic induction inside the TR08 vehicle [5]

\section{2) JR Maglev}

Regarding the Japanese Maglev system only limited information and data are available. The data used in the present comparison are taken mainly from Japanese literature.

The Japanese Maglev system makes use of modern superconducting magnets which allow for a larger gap, and repulsive-type Electro-Dynamic Suspension (EDS). Moving magnetic fields create a reactive force in a conductor because of the magnetic field effect. This force holds up the train. The maglev-train has superconducting magnetic coils, and the guide ways contain the levitation coils. The Maglev concept of the SCMAGLEV is illustrated in Fig. 5a, 5b [6].

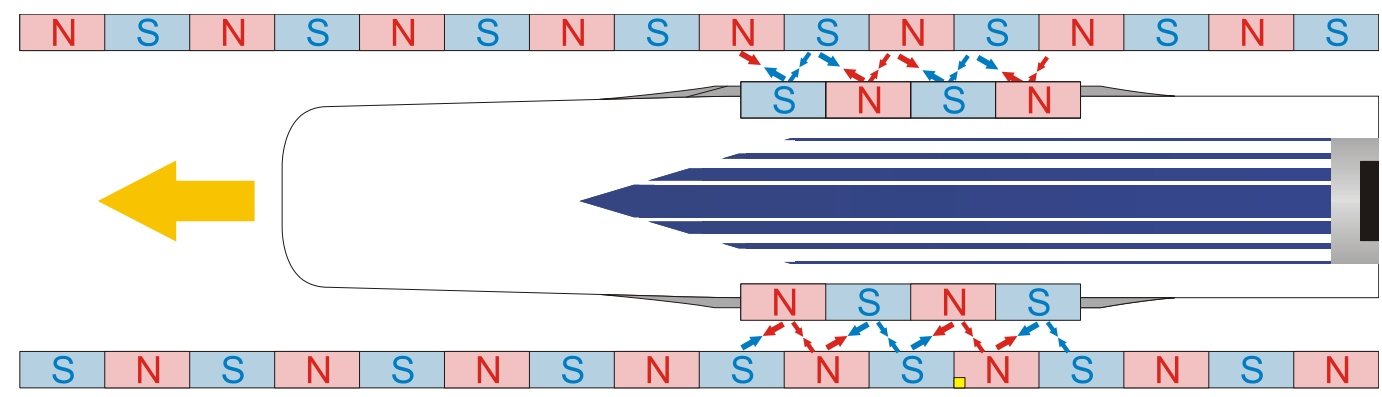

Fig. 5a. Propulsion concept of the superconducting MAGLEV [6]

The JR-Maglev train is driven by a Linear Synchronous Motor (LSM) System. This system is needed to supply power to the coils at the guide way. 


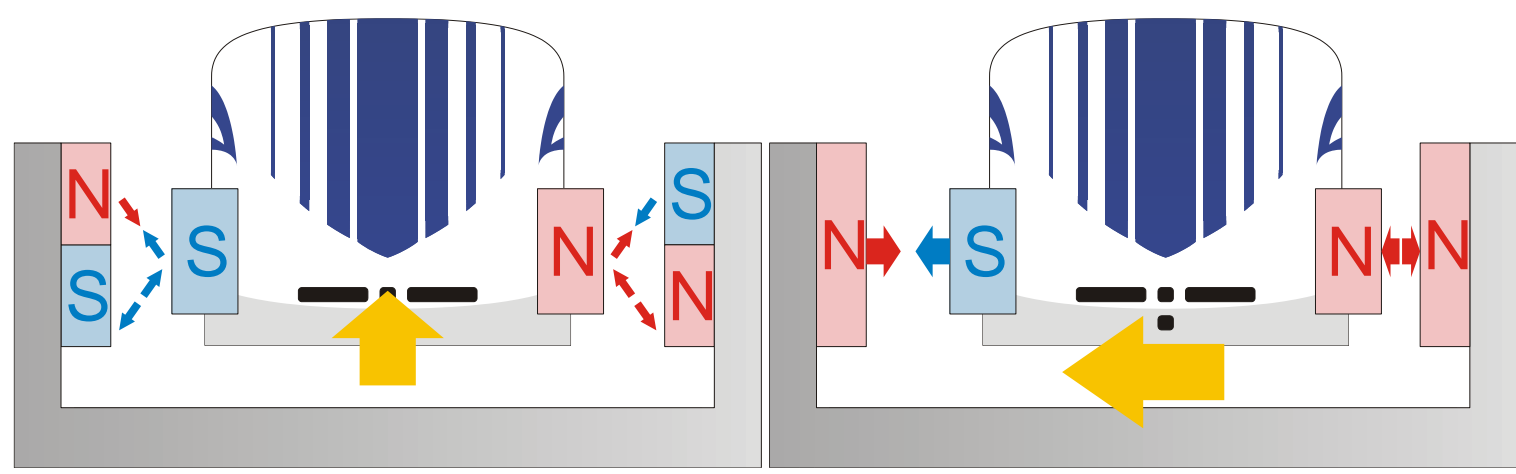

Fig. 5b. Levitation and guidance concept of the superconducting JR MAGLEV [6]

When the train is running at high speed, levitation coils on the guide way produce reactive forces in response to the approach of the superconducting magnetic coils onboard the trains. The EDS system has the advantage of larger gaps than the EMS system, but the EDS system needs support wheels which are required in low speed running, because the EDS system cannot produce a large levitation force at speeds below $150 \mathrm{~km} / \mathrm{h}$. However, once the train reaches a certain speed, the wheels will actually retract so that the train is floating. The Japanese MAGLEV system has a "self-stable" air gap of about $10 \mathrm{~cm}$, whereas the Transrapid with EMS system has an air gap of $1 \mathrm{~cm}$, which has constantly to be controlled. The levitation coils which are located along the guide way generate guiding and stabilizing forces. The following figure and tables are official data published in [7].

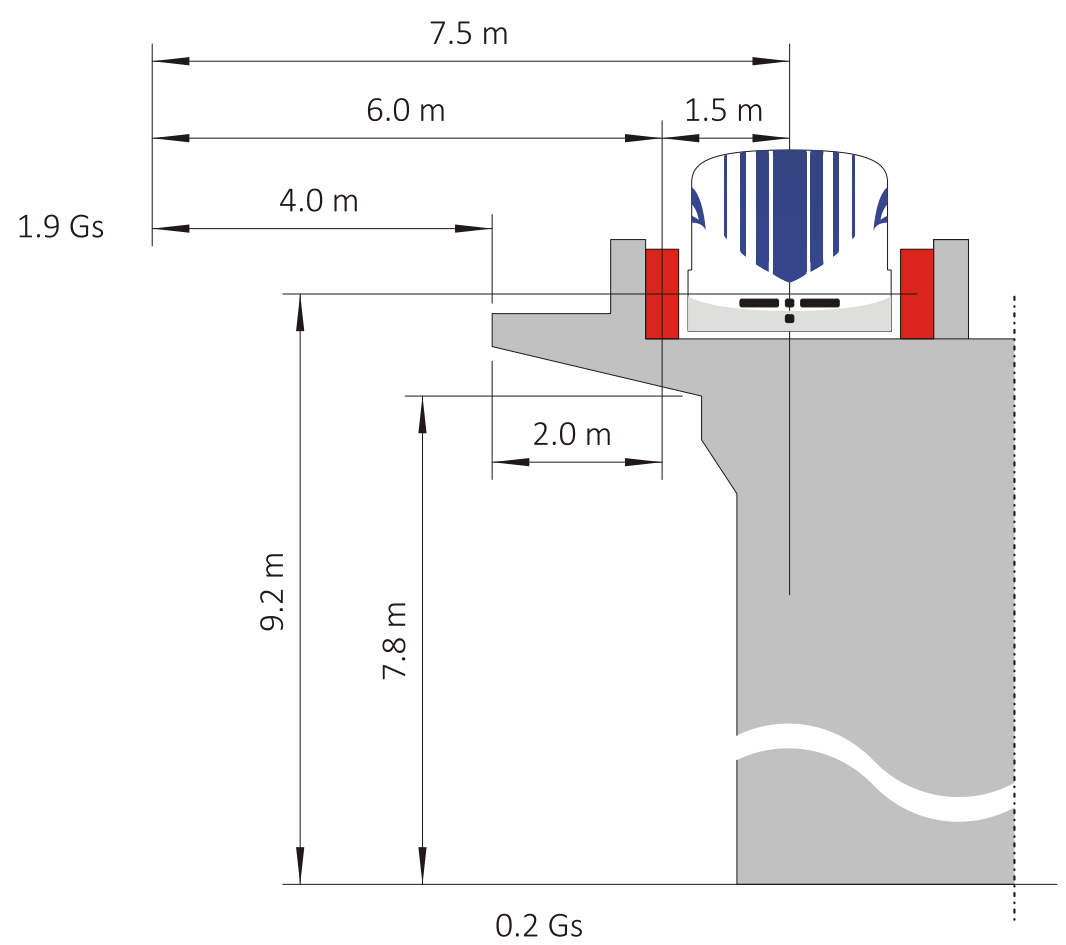

Fig. 6. Locations of the measurement points of the induction values. 
Table 2. Maximum induction values inside the vehicle (at different locations).

\begin{tabular}{|c|c|c|c|c|c|}
\hline Height & $\begin{array}{l}\text { Position } \\
\text { Condition }\end{array}$ & Gangway & $\begin{array}{l}\text { Inside of the vehicle } \\
\text { Passenger } \\
\text { compartm. } 1\end{array}$ & $\begin{array}{l}\text { Passenger } \\
\text { compartm. } 2\end{array}$ & $\begin{array}{l}\text { ICNIRP } \\
\text { guideline }\end{array}$ \\
\hline $1.5 \mathrm{~m}$ & \multirow{3}{*}{$\begin{array}{l}\text { Vehicle stop } \\
\text { Static field } \\
\text { Meas. equipm. 1 }\end{array}$} & $440 \mu \mathrm{T}$ & $\mathrm{X}$ & $310 \mu \mathrm{T}$ & \multirow{4}{*}{$400 \mathrm{mT}$} \\
\hline $1.0 \mathrm{~m}$ & & $810 \mu \mathrm{T}$ & $50 \mu \mathrm{T}$ & $370 \mu \mathrm{T}$ & \\
\hline \multirow[b]{2}{*}{$0.3 \mathrm{~m}$} & & $920 \mu \mathrm{T}$ & $40 \mu \mathrm{T}$ & $371 \mu \mathrm{T}$ & \\
\hline & $\begin{array}{l}\text { Vehicle running } \\
\text { Meas. equipm. } 1\end{array}$ & $900 \mu \mathrm{T}$ & $X$ & $430 \mu \mathrm{T}$ & \\
\hline
\end{tabular}

Table 3. Induction values inside the vehicle (Data taken from Miyzaki line).

\begin{tabular}{|l|r|r|r|}
\hline Measurement location & & w/o shielding & w shielding \\
\hline \multirow{4}{*}{ Center of seating row } & $1 \mathrm{~m}$ above floor & $116 \mu \mathrm{T}$ & $88 \mu \mathrm{T}$ \\
\cline { 2 - 4 } & seat level & $96 \mu \mathrm{T}$ & $64 \mu \mathrm{T}$ \\
\cline { 2 - 4 } & $0.1 \mathrm{~m}$ above floor & $112 \mu \mathrm{T}$ & $58 \mu \mathrm{T}$ \\
\hline \multirow{3}{*}{ Benter of gangway } & $1.5 \mathrm{~m}$ above floor & $90 \mu \mathrm{T}$ & $89 \mu \mathrm{T}$ \\
\cline { 2 - 4 } & $0.1 \mathrm{~m}$ above floor & $105 \mu \mathrm{T}$ & $83 \mu \mathrm{T}$ \\
\hline \multirow{3}{*}{ Gangway } & $1.0 \mathrm{~m}$ above floor & $1.656 \mu \mathrm{T}$ & $429 \mu \mathrm{T}$ \\
\cline { 2 - 4 } & $10 \mathrm{~cm}$ above floor & $1.764 \mu \mathrm{T}$ & $1.061 \mu \mathrm{T}$ \\
\hline \multirow{2}{*}{2.4 m from connection } & & & \\
\cline { 2 - 4 } & $1.5 \mathrm{~m}$ above floor & $134 \mu \mathrm{T}$ & $206 \mu \mathrm{T}$ \\
\cline { 2 - 4 } & $0.1 \mathrm{~m}$ above floor & $1.841 \mu \mathrm{T}$ & $366 \mu \mathrm{T}$ \\
\hline
\end{tabular}

Table 4. Static and alternating induction values outside along the Linear Shinkansen line at various locations

\begin{tabular}{|l|l|l|r|}
\hline \multicolumn{2}{|l|}{ Static field } & Measurement location & Magnetic induction \\
\cline { 3 - 4 } & & area $8 \mathrm{~m}^{2}$ under bridge & $20 \mu \mathrm{T}$ \\
\cline { 3 - 4 } & & area $4 \mathrm{~m}^{2}$ from guideway & $190 \mu \mathrm{T}$ \\
\cline { 3 - 4 } & along the guideway & $200 \mu \mathrm{T}$ \\
\cline { 3 - 4 } & Platform & $800 \mu \mathrm{T}$ \\
\cline { 3 - 4 } & max. inside vehicle & $1.330 \mu \mathrm{T}$ \\
\hline Alternating field & along the guideway & $200 \mu \mathrm{T}$ \\
\cline { 3 - 4 } & & generated max. by coil & $200 \mu \mathrm{T}($ at $100 \mathrm{~km} / \mathrm{h})$ \\
\cline { 2 - 4 } & Oropulsion & max. inside vehicle & $700 \mu \mathrm{T}($ at $20 \mathrm{~km} / \mathrm{h})$ \\
\hline
\end{tabular}

Table 5. Regulations given by the National Environmental Research Center of Japan

\begin{tabular}{|l|c|}
\hline Location & Max. Value of induction \\
\hline Directly above motor & $\max .600 \mu \mathrm{T}$ \\
\hline Inside vehicle above reactor at floor & $\max .4000 \mu \mathrm{T}$ \\
\hline $0.05 \mathrm{~m}$ under the motor & $\max .70000 \mu \mathrm{T}$ \\
\hline $0.15 \mathrm{~m}$ under the motor & $\max .20000 \mu \mathrm{T}$ \\
\hline
\end{tabular}


A system has been proposed to reduce the magnetic field inside the vehicles of Superconducting Maglev Train by shielding measures [8]. Grain Oriented silicon steel (GO) has a high saturated magnetic flux density and also higher permeability than pure iron. So this is suitable as the material of magnetic shielding at the target level of less than $500 \mu \mathrm{T}$. The challenge consists in handling the magnetic anisotropy of this material. To avoid the problem of anisotropy a bi-lamellar shielding has been proposed to the coach. The outer shielding material is pure iron and the inner one is permalloy $\mathrm{B}$, which has a relatively high saturated magnetic flux density in all categories of permalloy and has magnetic isotropy. The magnetic field in this double shielding system reaches a maximum value of $300 \mu \mathrm{T}$ locally, but is less than $100 \mu \mathrm{T}$ in almost all regions inside the vehicle. This maximum value corresponds to an open space without shielding, through which passengers can move from coach to corridor. The disadvantage of this bi-lamellar shielding is the increase in the weight of magnetic shield system. There still might be some room for further optimizing the shielding configuration in order to reduce the weight.

In order to evaluate the environmental concerns related to electromagnetic fields of high speed transportation systems we have to compare the maximum magnetic induction inside the vehicles at the location of passenger seats. Fig. 7 shows the maximum induction values to which passengers are exposed during the ride in the high speed transportation systems of this comparison, together with the corresponding limits.

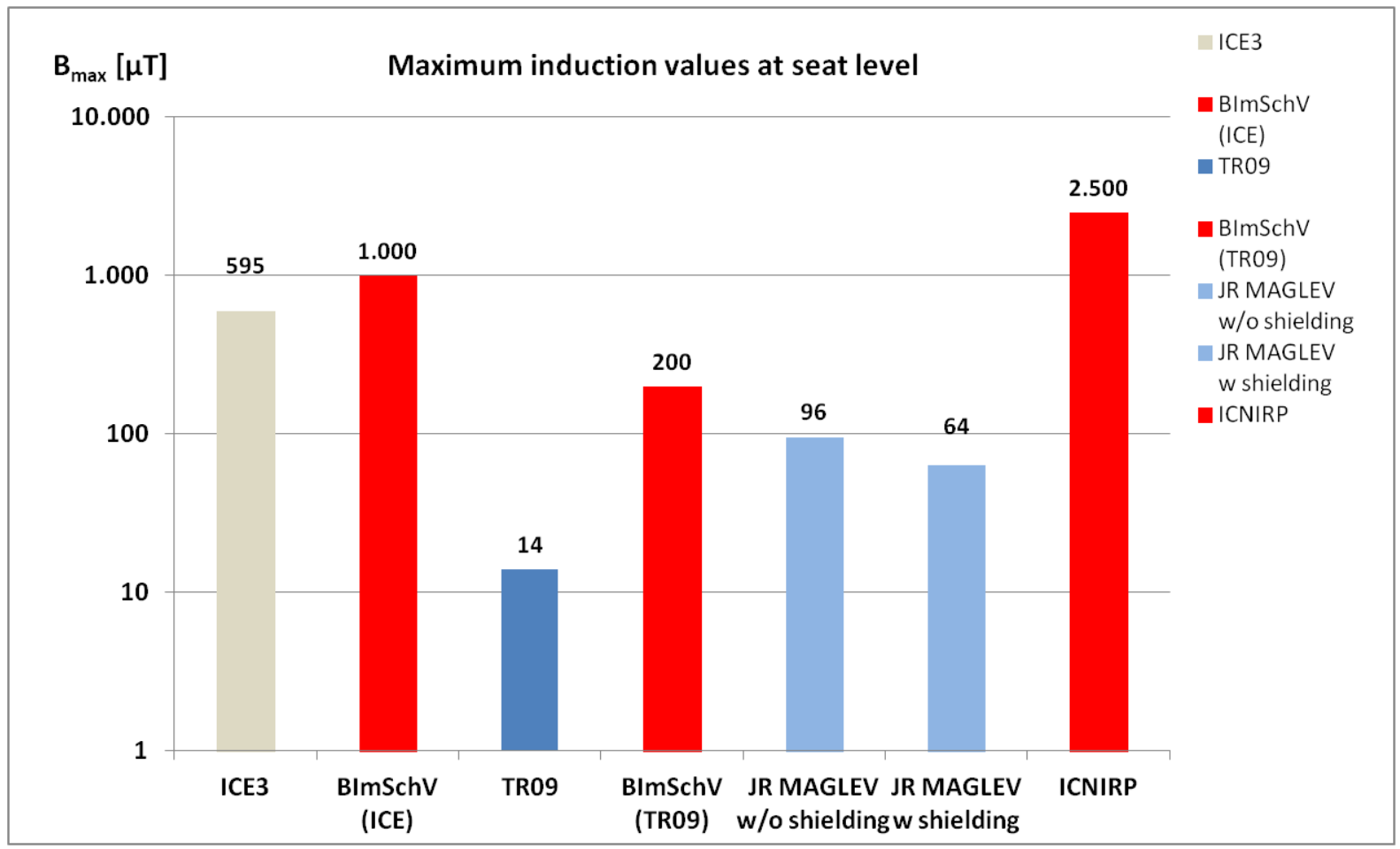

Fig. 7. Comparison of the maximum induction values inside the vehicle at passengers position. The red columns are the corresponding limits given by BImSchV and ICNIRP, respectively 
The values are represented on a logarithmic scale due to the high limit of ICNIRP. All induction values remain under the limits.

\section{CONCLUSION}

In the article, the electromagnetic fields generated by the power supply of high speed transportation systems have been calculated and compared. Since the biological effect of the peak electrical field strength of $1 \mathrm{kV} / \mathrm{m}$ is considered as negligible, the focus of the comparison was especially on the magnetic field which is more critical than the electrical field.

The worst case calculation for the railway system ICE results in induction values of about $600 \mu \mathrm{T}$, which is well below the limit given by BImSchV. Therefore, the power supply system of railway systems has no negative impact on passengers as well as on the environment.

In case of the high speed magnetic levitation transportation systems, the situation is different. The magnetic field strength strongly depends on the technology used for levitation, propulsion and guidance. In the case of Transrapid past investigations based on experimental measurements show that there is no negative impact of the magnetic induction on passengers and the environment to be expected. For comparison, the value of the magnetic field of earth at central Europe is $48 \mu \mathrm{T}$, which is more than 3 times the measured value in the Transrapid.

In case of the Japanese Maglev system, which uses superconducting magnets and a wide air-gap, considerable efforts are necessary to shield passengers from the high magnetic field strength. However, with present shielding measures the induction values inside the vehicle of the Maglev systems are 4 to 6 times higher than inside the Transrapid vehicle. In addition, the material for shielding high magnetic fields has the drawback of heavy weight, which has a negative influence on the energy balance. Research in Japan is focusing on new and innovative materials to reduce weight without loss of shielding properties.

\section{References}

1. Electromagnetic fields at workplaces, Final Report, FB400-E, Federal Ministry of Labour and Social Affairs, Nov. 2011, ISSN 0174-4992.

2. Binder A, Körner O. Was treibt den ICE 3 und den Transrapid. Darmstadt: Institut für Elektrische Energiewandlung; 2011.

3. August P. Optimierungsstrategie für den Antrieb des Transrapid, [Dissertation]. Dresden; 2010.

4. Bühler G, Czainski R. CPS for the high-speed magnetic levitation system of Transrapid TR08, 2005.

5. Rausch C. Zevrail, Glasers Annalen - Sonderheft Transrapid, 2003.

6. The Review "Superconducting Maglev (SCMAGLEV)". JR Central, 2017. 
7. Linear Shinkansen abunai, Linear Community Net, ISBN 978-4-8461-1315-5. 2014 May 30 (In Japanese).

8. Sasakawa T, Tagawa N. Reduction of Magnetic Field in Vehicle of Superconducting Maglev Train. IEEE Transactions on Magnetics. 2000;36(5):3676-3679. doi: $10.1109 / 20.908938$

\section{Information about the authors:}

Kircher Roland, Dr., The International Maglev Board;

ORCID: 0000-0002-8807-8915;

E-mail: rk@maglevboard.net

Klühspies Johannes, Dr. habil. Dr. h.c., full professor;

ORCID: 0000-0001-6089-9853;

E-mail: jok@maglevboard.net

Palka Ryszard, Prof. Dr.;

ORCID: 0000-0003-3509-6500;

E-mail: rpalka@zut.edu.pl

Fritz Eckert, Dipl. Eng, ORCID: 0000-0003-3422-227X;

E-mail: ef@bahntechnik.de

Eiler Kenji, Dipl. Eng.;

E-mail: kenji.eiler@maglevboard.net

Witt Michael, Dipl. Eng.;

E-mail: mikewitt@maglevboard.net

To cite this article:

Kircher R, Klühspies J, Palka R, et al. Electromagnetic Fields Related to High Speed Transportation Systems. Transportation Systems and Technology. 2018;4(2):152-166. doi: 10.17816/transsyst201842152-166 